\title{
Immunohistochemical Changes of Liver Fasciolosis in Cattle and Sheep in Jeddah, Saudi Arabia
}

\begin{abstract}
Background: Fasciolosis is a crucial helminthes disease caused by two trematodes of the genus Fasciola: Fasciola hepatica (temperate liver fluke) and Fasciola gigantica (tropical liver fluke).

Methods: A cross-sectional study was conducted on cattle and sheep in a slaughterhouse to detect animals infected with Fasciolosis. Liver samples were collected from infected animals and transferred to the laboratory for histopathological and immunohistochemical examinations.

Result: Microscopically, the liver sections were showed extensive fibrous connective tissue surrounding the central vein and portal area with extensive thickening of bile ducts wall and fibrosis. Marked infiltration of inflammatory cells was also seen.

Key words: Biliary cirrhosis, Fasciolosis, Histopathological, Immunohistochemical.
\end{abstract}

\section{INTRODUCTION}

Parasitic diseases are the major impediment in the growth and development of livestock health (Salmo, 2014). Fasciolosis is an important zoonotic disease widespread in animals and human beings, crucial to the economy and health (Najib et al. 2020). The Fasciola hepatica and Fasciola gigantica cause fasciolosis. It is a neglected tropical disease and in more than 50 countries, most cattle and sheep are reared (Mehmood et al. 2017).

Fasciola hepatica and Fasciola gigantica are the two liver flukes commonly reported to cause Fascioliasis in ruminants. The disease is caused by the ingestion of encysted metacercaria of liver flukes (Ibrahim, 2017). Fasciola hepatica is found in sheep and cattle and is widely distributed in Europe, Africa, Asia, Oceania and North and South America (Adarosy et al. 2013).

The liver is the most important organ for animal health and animal development since much of the body's metabolism occurred in the liver. The liver parasite infections are one of the critical factors that decrease national income in animal production by either directly denouncing the pathologically-affected liver or by indirectly influencing animal growth and meat production (El-Hallawany and Abdel-Aziz, 2012).

The adult Fasciola resides in the gall and bile ducts of infected animals leading to serious damage to animals. Subclinical and chronic disease usually results in decreased production of meat, milk and wool. Secondary bacterial infections, fertility problems and great expenses of anthelmintics should be considered (Degheidy and AlMalki, 2012).

In rejecting the Fasciola hepatica infection and developing successful resistance to re-infection, there seems to be an essential part of the humoral and cellular immune response to the parasite. During their hepatic migration, the local immune response to young flukes may
'Department of Biology, College of Science, University of Jeddah, Jeddah, Saudi Arabia.

${ }^{2}$ Department of Epidemiology, Faculty of Public Health and Health Informatics, Umm Al-Qura University, Saudi Arabia.

Corresponding Author: Khalil Mohamed, Department of Epidemiology, Faculty of Public Health and Health Informatics, Umm Al-Qura University, Saudi Arabia.

Email: khali72@gmail.com

How to cite this article: Alsulami, M. and Mohamed, K. (2021). Immunohistochemical Changes of Liver Fasciolosis in Cattle and Sheep in Jeddah, Saudi Arabia. Indian Journal of Animal Research. 55(12): 1484-1490. DOI: 10.18805/IJAR.B-1341.

Submitted: 19-12-2020 Accepted: 01-07-2021 Online: 12-08-2021

have a role in the resistance mechanisms. Lymphocytic infiltration of hepatic lesions has mainly consisted of CD4+ cells in the sheep during the early stages of infection, while CD8+ lymphocytes have been increasing in chronic infection and reinfection over CD4+ (Perez et al. 1998).

Therefore, this research was intended to analyze the histopathological and immunological reactions induced in the liver of cattle and sheep naturally infected with Fascioliasis.

\section{MATERIALS AND METHODS}

\section{Study area}

The current research was a cross-sectional study carried out in one of the biggest abattoirs in Jeddah province in western region in Saudi Arabia. Examining of the slaughtered cattle and sheep to detect Fasciola spp in the liver was done periodically in the abattoir. A bout 150 cattle and 200 sheep were investigated. From these animals about 15 infected livers were collected from cattle and 25 infected livers were collected from sheep. The amount of worms in the gall bladder was ranged between 1-5 worms. 


\section{Sampling}

Examination of slaughtered cattle and sheep after skinning the slaughtered cow and sheep, the outer surface of the carcass was examined by visual observation for any abnormal lesion. Then the abdominal cavity was opened to check on internal organs. From each cow and sheep, the liver was inspected by making multiple deep incisions in the lobes and the gallbladder was opened using a knife (Fig 1). Observations were confirmed and the help of veterinary doctors was acquired throughout the inspection visits.

\section{Histological examination}

The liver samples of cattle and sheep were fixed in $10 \%$ neutral formalin for histopathological examinations. Then samples were dehydrated in ascending grades of alcohol. After that, the samples were embedded in paraffin wax. Sections of 5-micrometer thickness were prepared and subjected to staining with Hematoxylin and Eosin (H\&E) (Bancroft and Gamble, 2008) for routine histological examination. The silver stain of Gordon and Sweet was used for displaying irregular reticular fibers, which may indicate cirrhosis or liver necrosis (Gordon and Sweets, 1936).

\section{Immuno-histochemical examination}

The paraffin liver sections were deparaffinized and hydrated. Incubation with $3 \%$ hydrogen peroxide for 5 minutes blocked endogenous peroxidase activity. Sections were incubated overnight with CD4+ and CD8+ monoclonal antibody (purchased from veterinary diagnostic test kits and reagents (VMRD Inc), Pullman, WA, USA). In a separated tissue sections, each primary antibody was added. The monoclonal antibody was then linked to the biotinylated goat anti mouse immunoglobulin serum (purchased from Dako Denmark A/S) for 30 minutes. A brown reaction was formed after 5 minutes of exposure to 3,3-diaminobenzidine tetrahydrochloride solution (DAB) (purchased from Sigma_, St Louis, MO, USA), then washing with distilled water. Sections were countered-stained with hematoxylin (Behairy et al. 2018).

\section{RESULTS AND DISCUSSION}

Fascioliasis is an endemic disease globally and causes severe economic conditions and affects large and small animals. Fascioliasis was the leading cause of liver damage and was responsible for full sheep (Degheidy and Al-Malki, 2013) and cattle liver condemnation (Okoye et al. 2015).

In the current study, lesions were mostly around portal spaces with the extensive characteristic proliferation of fibrous connective tissue around the intra-hepatic bile ductules with peri-infiltration of mononuclear inflammatory cells as was reported by (Ashrafi et al. 2014; Labruna et al. 2018; Mendes et al. 2012). Besides, these findings were similar to the finding of Aljameel et al. (2017). They reported that the thickening of the bile duct is due to the chronic nature of Fasciola infection (Aljameel et al. 2017).
In the present study, the liver tissue's histological structures appeared similar in both the cattle and sheep. The HandE liver sections of cattle and sheep exhibited dilated congested central vein with marked deeply acidophilic materials surrounding the central vein. Most of the hepatocytes have a deep acidophilic cytoplasm with apoptotic nuclei. There was a pronounced inflammatory cellular infiltration across the central veins and close to the portal tracts in infected animals' liver sections. Often this invasion has spread to the hepatocytes. There were no hepatocytes in areas of heavy cellular infiltration, only an acidophilic region (Fig 2). An extensive reticular fibers with hyperplasia of bile duct walls, which produced a thick wall picture, was marked in sheep and cows infected liver. These results in agreement with previous studies by (Okoye et al. 2015; Salmo, 2014), who proved that thickening of the bile duct is due to the chronic nature of Fasciola infection and the presence of mature flukes within the lumen of intrahepatic bile ducts which brought a continuous irritation and led to hyperplastic proliferation (Okoye et al. 2015; Salmo, 2014).

An additional section showed major hepatocytes swelling that existed with clear cytoplasm. The nuclei relocated or disappeared from the cell's usual location. The intra-sinusoidal cells, Kupffer cells, were hypertrophied (Fig 3). The portal area revealed a portal vein and a large proliferated, thick-walled bile duct surrounded with the nuclei of the cellular infiltrate (Fig 4). Primary biliary cirrhosis
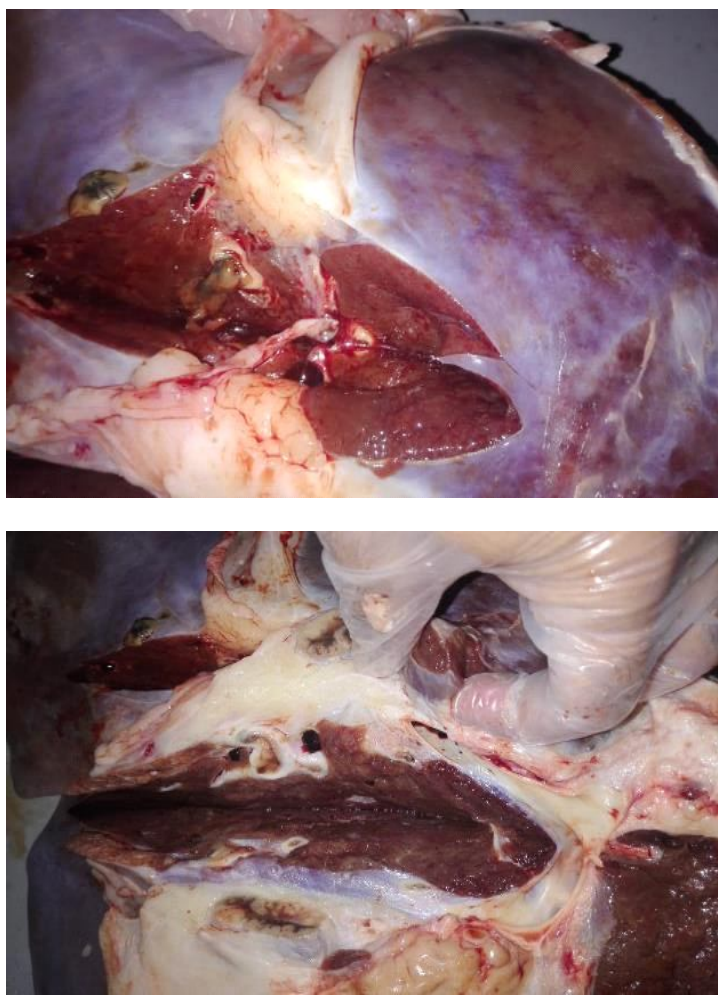

Fig 1: Caw and sheep liver inspection by making multiple deep incisions in the lobes and the gallbladder was opened using a knife. 
showed extensive proliferation of fibrous connective tissue around the intrahepatic bile ductules with peri-infiltration of the bile duct's mononuclear inflammatory cells. The thickening of bile ducts wall and surrounded by fibrous connective tissues and metaplasia of bile ducts with infiltration of inflammatory cells (Fig 5).

A marked hepatic infiltration with mononuclear inflammatory cells was also observed in this study. The formation of granuloma was also observed mainly near the portal area. These results were similar to the results detected by Okoye et al. (2015). Okoye et al. (2015) reported that the granulomatous reaction formed mainly of mononuclear infiltration in the form of eosinophils, macrophages and lymphocytes with overcrowded endothelial cells and fibroblast cells. They mentioned that these mononuclear infiltrations cells were considered the prominent features in the early stage and also the migratory phase of infection. Moreover, our results agree with the previous study done, which proved that immature liver flukes' migration through the tissue causes hemorrhage and irritation and brought the cellular inflammatory reactions (Salmo, 2014). In addition, the present study revealed hypertrophied von-kupffer cells in the dilated blood sinusoids. This could be explained by (Lee and Friedman, 2011; Liu et al. 2010), who reported that Kupffer cells are associated with hepatocellular apoptosis, inflammation and fibrosis in liver fibrosis models.

In Gordon and Sweet reticulin stained sections, the reticular fibers in the stroma display a marked rise. Reticular fibers were observed as thin black structures appeared to rise in the area surroundings the central veins (Fig 6 and 7) and the structures in the portal area (Fig 8 and 9).

Immunohistochemically stained sections with CD 4 (Fig 10 and 11) and CD8 (Fig 12 and 13) showed a positive brownish reaction of CD4 and CD8 T- lymphocytes inbetween the hepatocytes in the dilated blood sinusoids surrounding the central vein. In addition, positive brownish reactions are located mainly in the inflammatory cells infiltrations area of portal spaces.

The best-characterized function of intrahepatic lymphocytes is their high cytotoxic activity toward other cells. Several previous studies have investigated the immune response to Fasciola hepatica in sheep. These studies reported that sheep do not develop resistance to reinfection (Mehal et al. 2001; Moreau et al. 2002).

The cellular immune response in sheep and cow to an infection with Fasciola hepatica were examined by immunohistochemistry of liver tissue. Interestingly, the presence of numerous activated CD4+ and CD8+ Tlymphocytes in the portal tract area, in-between the radiating hepatocytes and surrounding bile ducts, were marked observed in the present study. Similarly to studies done by Mendes et al. (2010); Molina and Skerratt, (2005) and Pérez et al. (2002). In addition, Zafra et al. (2010) reported that the heavy infiltration of CD2+, CD4+ and CD8+ T lymphocytes, both in hepatic lesions and hypertrophied

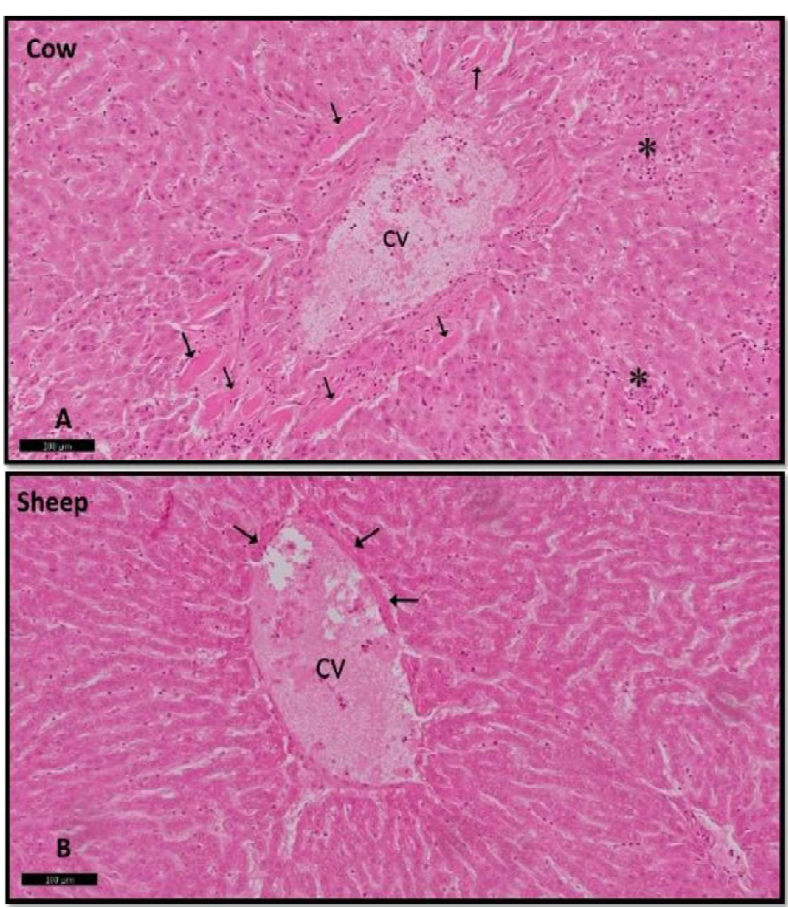

Fig 2: Liver sections shows dilated congested central vein (CV) surrounded with marked deeply stained acidophilic materials ( $\uparrow$ ) and marked infiltration of inflammatory cells $\left(^{*}\right)$. (H\&E $\left.\times 10\right)$.

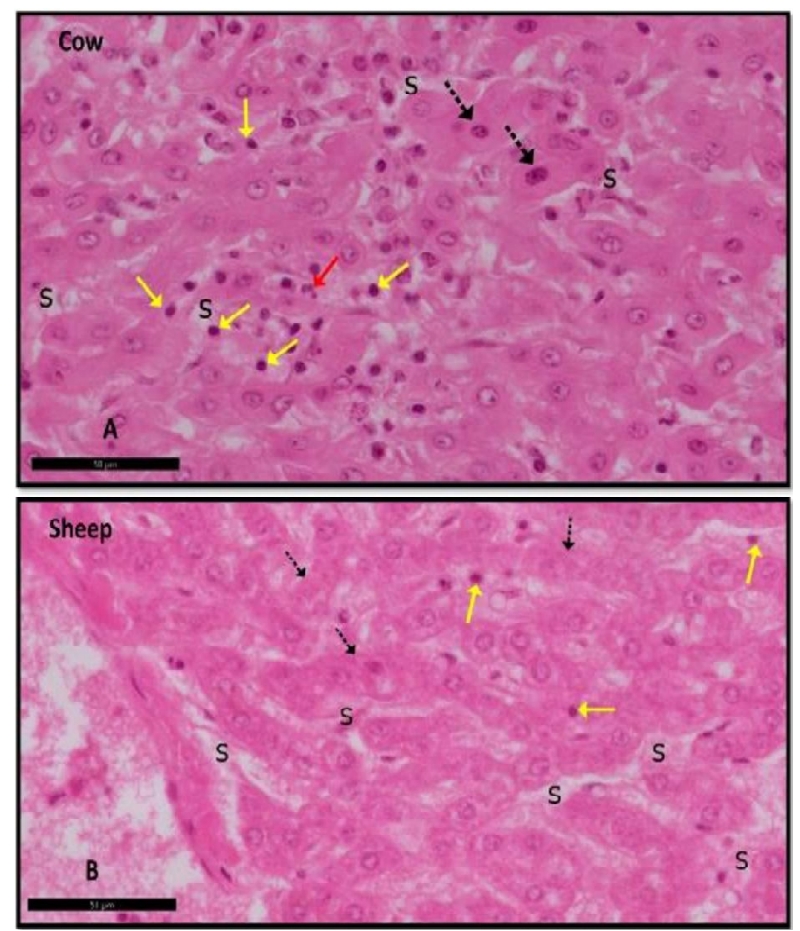

Fig 3: Liver sections shows focal aggregation of mononuclear inflammatory cells between the hepatocytes (red $\uparrow$ ) with deep acidophilic cytoplasm and small shrunken deeply stained nuclei (dot arrow) and the hypertrophied intra-sinusoidal cells (Von Kupffer cells) (yellow arrow) in-between hepatocytes within the dilated blood sinusoids (s). (H\&E $\times 40)$. 


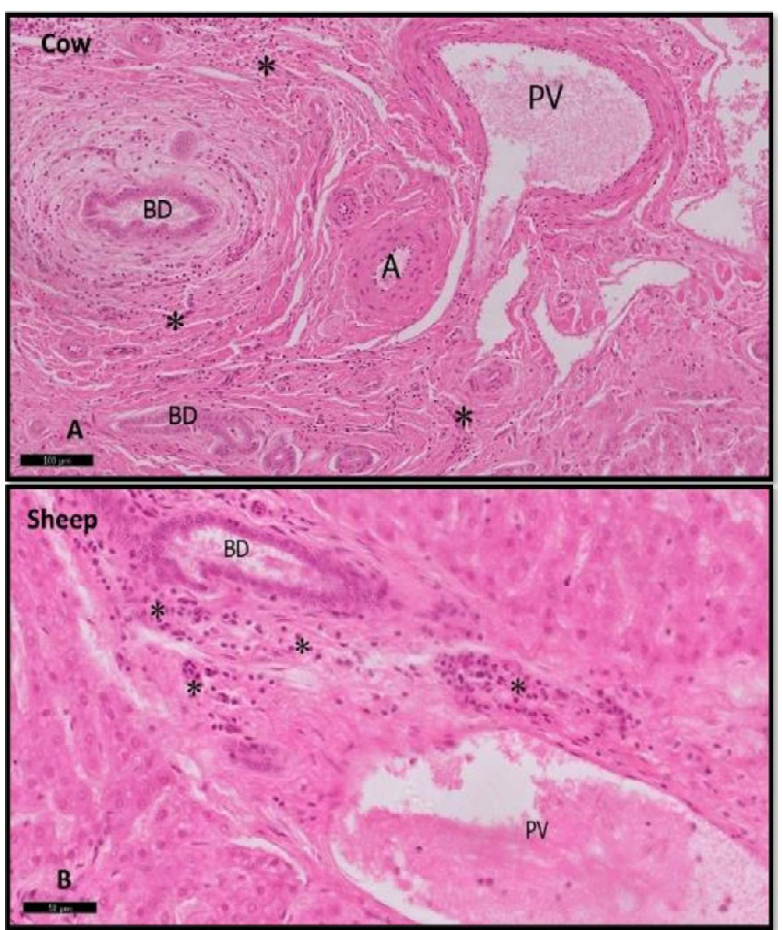

Fig 4: Liver sections shows portal area with dilated congested portal vein (PV), portal artery (A) and extensive proliferation of fibrous connective tissue around the intra-hepatic bile ductules $(\mathrm{BD})$ with extensive infiltration of mononuclear inflammatory cells $\left({ }^{*}\right) .(H \& E \times 20)$.

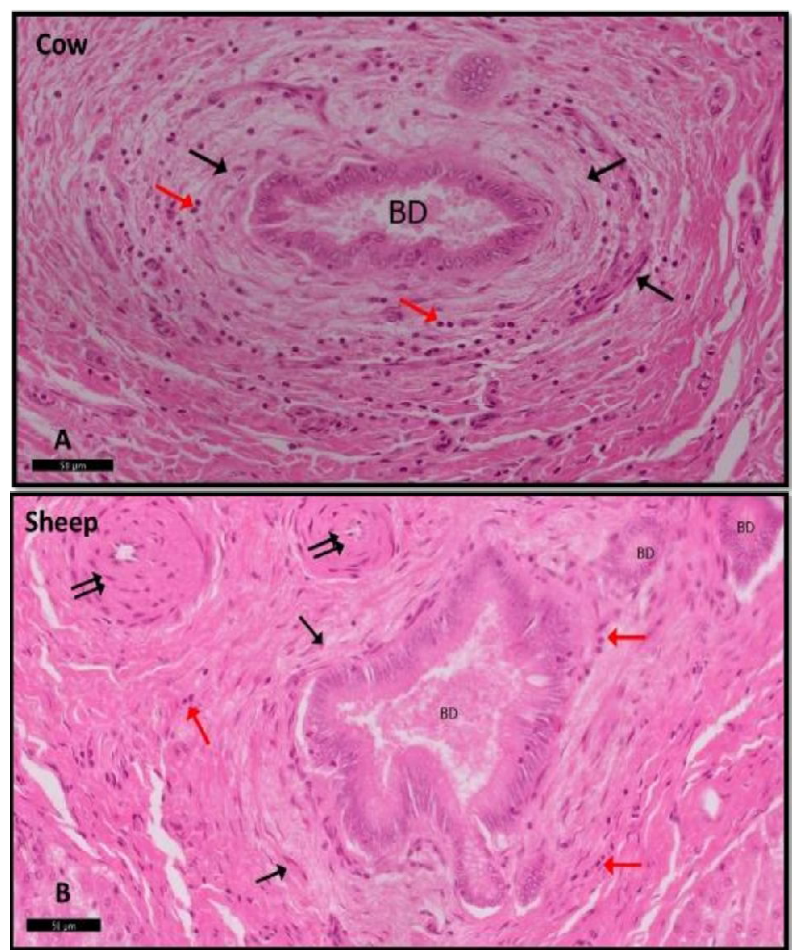

Fig 5: Primary biliary cirrhosis which shows extensive proliferation of fibrous connective tissue $(\uparrow)$ around the intra-hepatic bile ductules (BD) with peri-infiltration of mononuclear inflammatory cells (red $\uparrow)$. Notice granuloma formation $(\uparrow \uparrow) .(H \& E \times 20)$.

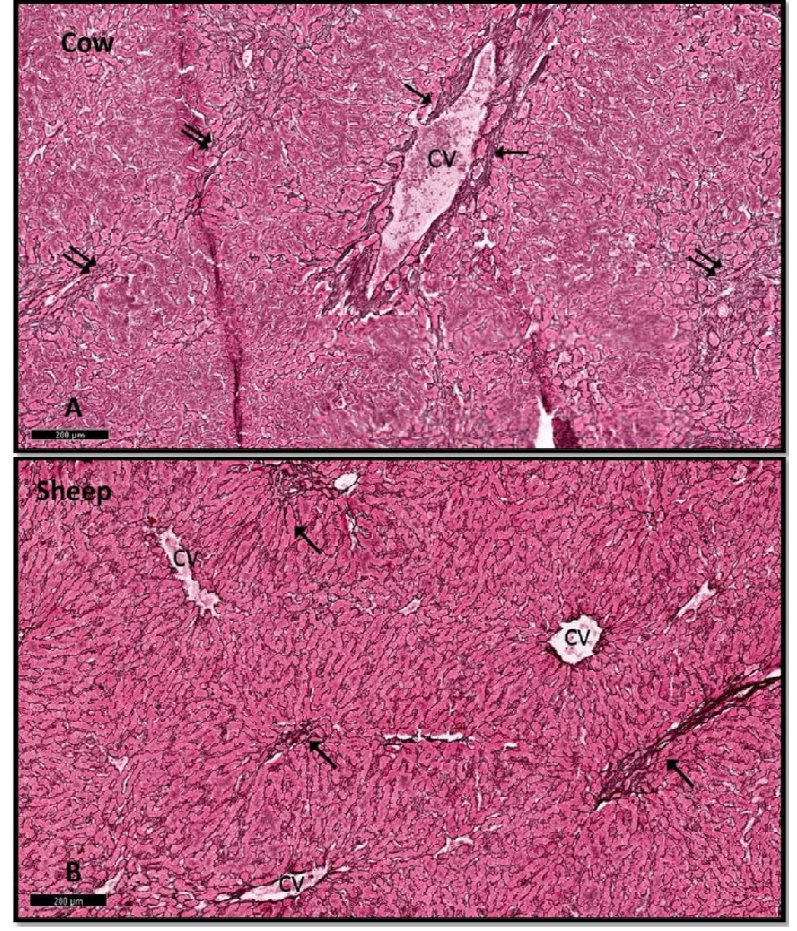

Fig 6: Condensed black stained fibers $(\uparrow)$ between the radially arranged hepatocytes and around the central vein (CV).

(Reticulin stain $\times 5$ ).
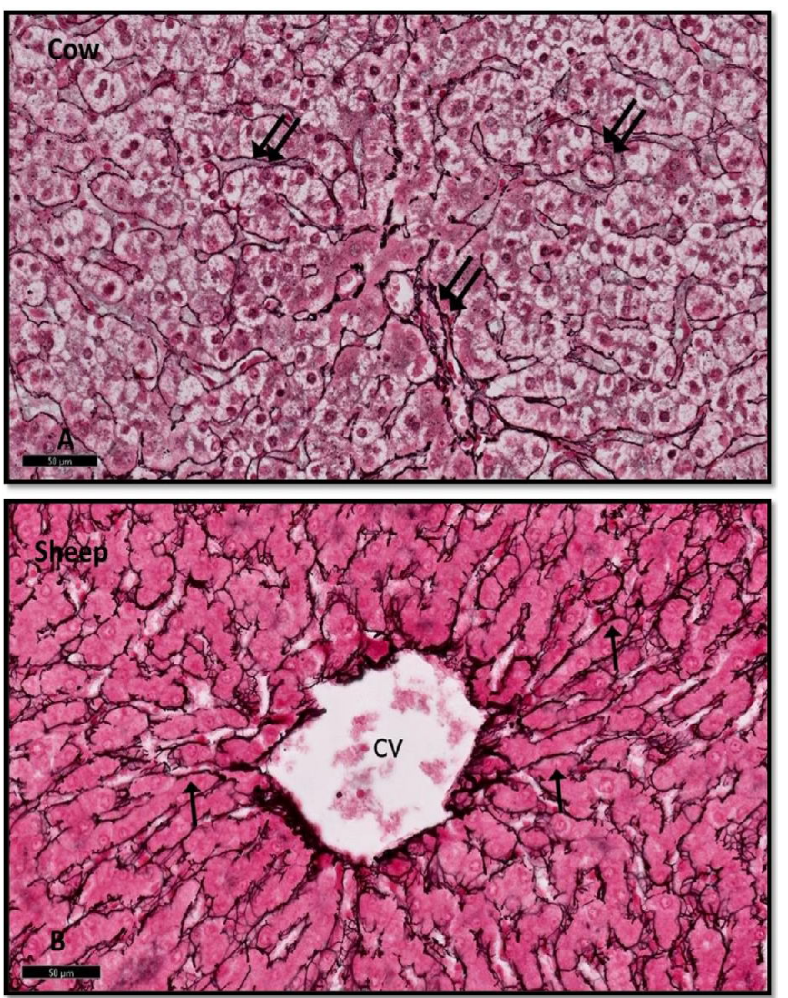

Fig 7: higher magnification of the previous sections shows condensed black stained fibers $(\uparrow)$ between the radially arranged hepatocytes and around the central vein (CV).

(Reticulin stain $\times 20$ ). 

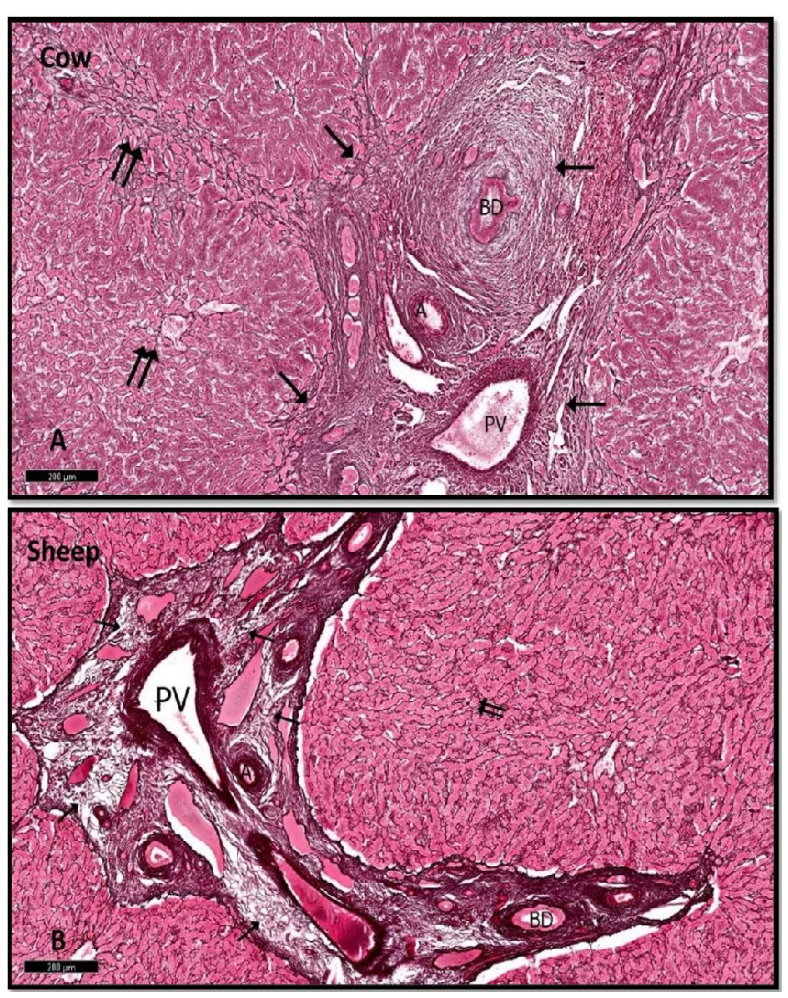

Fig 8: Condensed black stained fibers $(\uparrow)$ between the radially arranged hepatocytes $(\uparrow \uparrow)$ and in the portal area surrounding portal vein $(P V)$ and bile duct $(B D)$. (Reticulin stain $\times 5$ ).
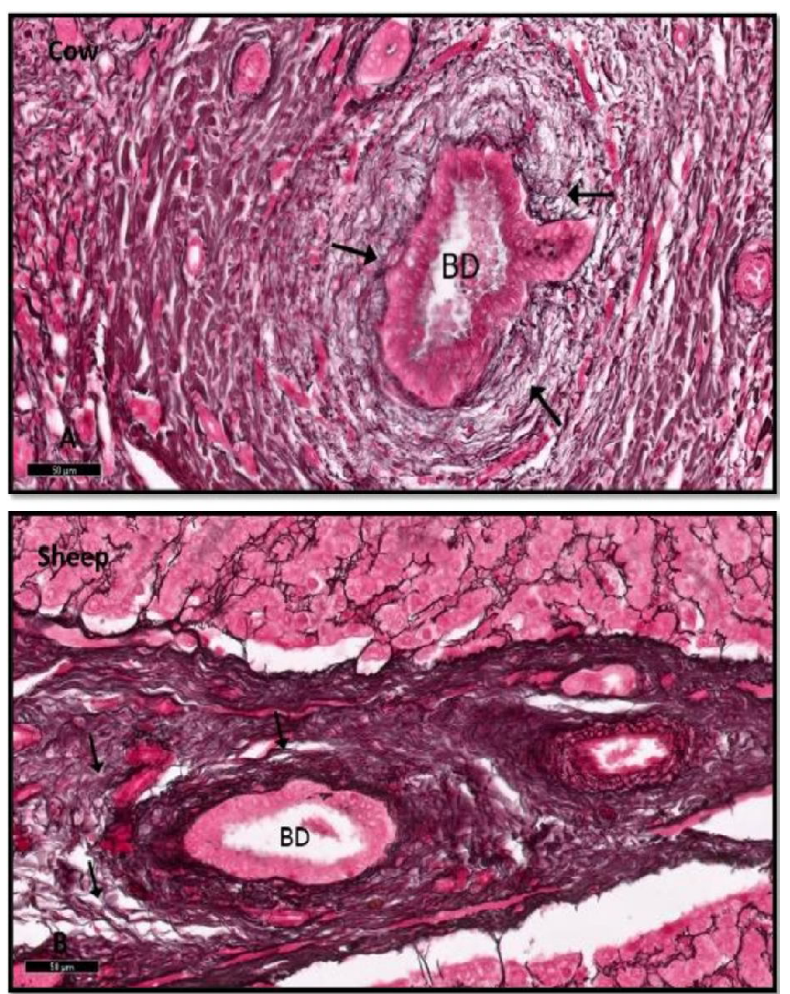

Fig 9: Higher magnification of the previous sections shows condensed black stained fibers $(\uparrow)$ between the radially arranged hepatocytes and around the bile duct (BD). (Reticulin stain $\times 20$ ).
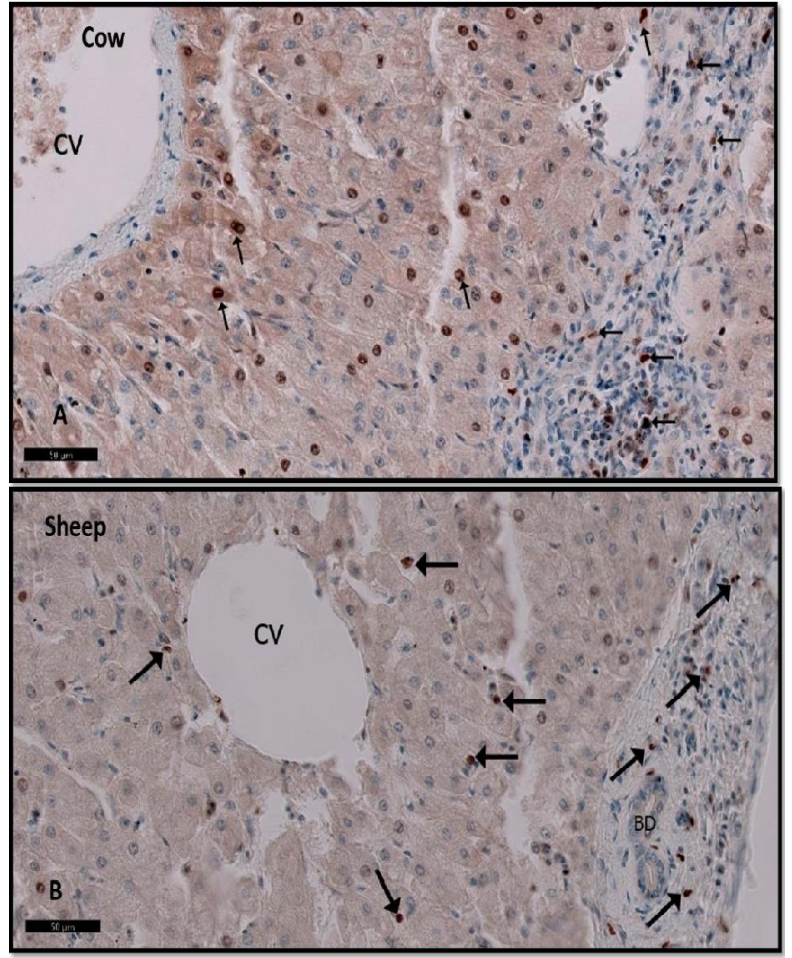

Fig 10: Immunohistochemical analysis of CD4 T-cell expression in the infected cow and sheep shows an apparent marked increase of the positive brownish cells $(\uparrow)$ in between the radiated hepatocytes around central vein $(\mathrm{CV})$ and the area of aggregated inflammatory cells. (CD4 Immunohistochemical stain $\times 20$ ).
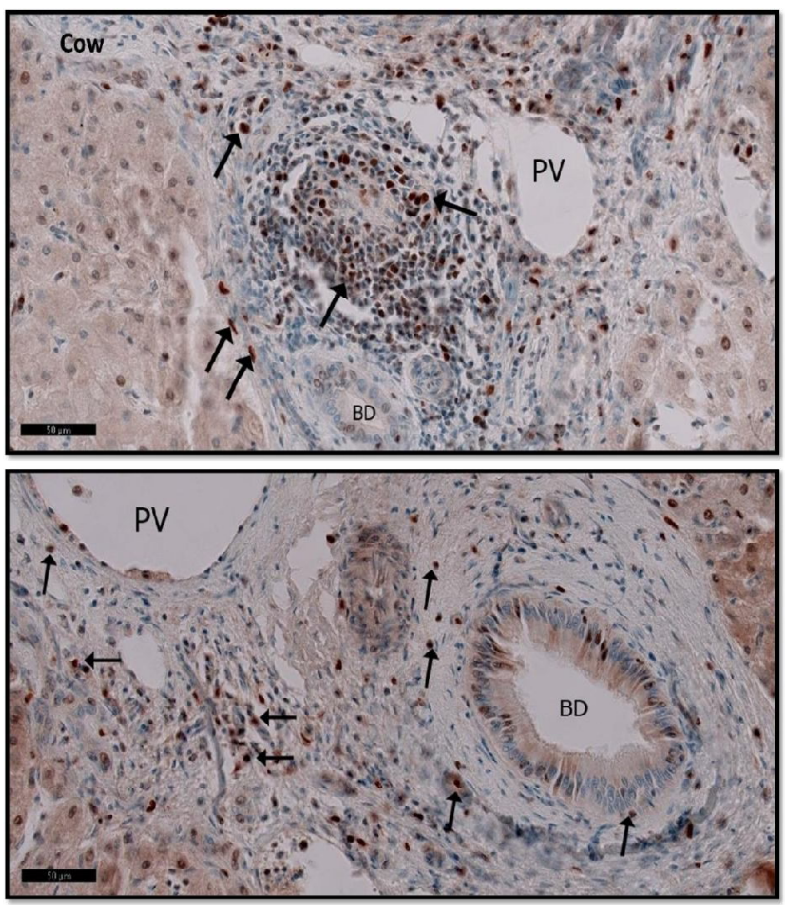

Fig 11: Immunohistochemical analysis of CD4 T-cell expression in the infected cow and sheep shows an apparent marked increase of the positive brownish cells $(\uparrow)$ around portal vein $(P V)$ and bile duct (BD). (CD4 Immunohistochemical stain $\times 20)$. 

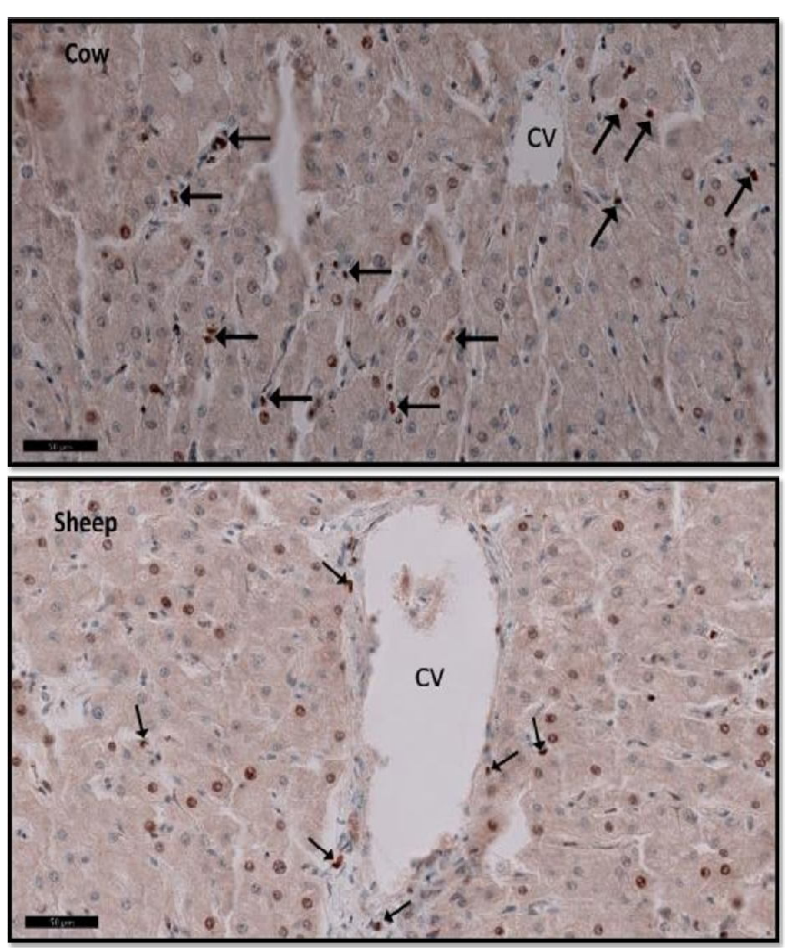

Fig 12: Immunohistochemical analysis of CD8 T-cell expression in the infected cow and sheep shows an apparent marked increase of the positive brownish cells $(\uparrow)$ in between the radiated hepatocytes around central vein (CV) and the area of aggregated inflammatory cells. (CD8 Immunohistochemical stain $\times 20$ ).

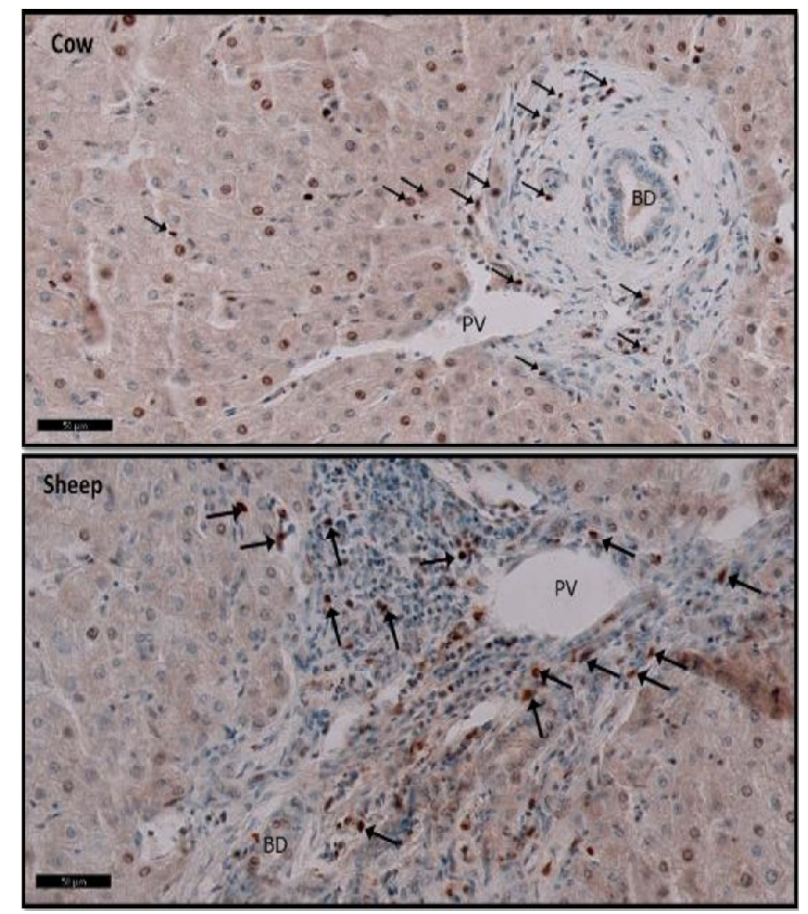

Fig 13: Immunohistochemical analysis of CD8 T-cell expression in the infected cow and sheep shows an apparent increase of the positive brownish cells $(\uparrow)$ in between the hepatocytes around portal vein (PV) and surrounding the bile duct (BD).

$($ CD8 Immunohistochemical stain $\times 20$ ). lymph nodes of infected goats suggested a strong local cellular immune response against flukes located within bile ducts.

\section{CONCLUSION}

The current study revealed that Fascioliasis's most common lesions were biliary cirrhosis with marked mononuclear cellular infiltrations. Moreover, the histopathological changes in the livers of cattle and sheep infected with Fasciola hepatica represented cell damage, leading to severe economic losses in animals and could lead to massive health conditions in humans.

\section{REFERENCES}

Adarosy, H.A., Gad, Y.Z., El-Baz, S.A. and El-Shazly, A.M. (2013). Changing Pattern of Fascioliasis Prevalence Early in the $3^{\text {rd }}$ Millennium in Dakahlia governorate, Egypt: An update. Journal of the Egyptian Society of Parasitology. 240(1412): $1-12$.

Aljameel, M.A., Bakhiet, A.O. and Osman, H.M. (2017). Histopathological Characteristics of Liver Fasciolosis in Camels at Nyala Abattoirs (2017). $3^{\text {rd }}$ International Scientific Conference of Camel Research and Production (ISCCRP), Khartoum-Sudan, 21 $1^{\text {st }}-23^{\text {rd }}$ November 2017.

Ashrafi, K., Bargues, M.D., O'Neill, S. and Mas-Coma, S. (2014). Fascioliasis: A worldwide parasitic disease of importance in travel medicine. Travel Medicine and Infectious Disease. 12(6): 636-649.

Bancroft, J.D. and Gamble, M. (2008). Theory and Practice of Histological Techniques. Elsevier Health Sciences.

Behairy, B.E., Ehsan, N., Anwer, M., Allam, A., El-Henawy, I., Hameed, N.A. and Zakaria, H.M. (2018). Expression of intrahepatic CD3, CD4 and CD8 T cells in biliary atresia. Clinical and Experimental Hepatology. 4(1): 7-12.

Degheidy, Nabila, S. and Al-Malki, J.S. (2012). Epidemiological studies of fasciolosis in human and animals at Taif, Saudi Arabia. World Appl. Sci. J. 19: 1099-1104.

Degheidy, Nabila, S., Sharaf, E.M. and Al-Malki, J.S. (2013). The incidence of Fasciolasis and some types of bacteria incurred causing lack meat and livers quality of slaughtered animals at Al-Taif, KSA. Assiut. Vet. Med. J. 59(139): 136-141.

El-Hallawany, H.A. and Abdel-Aziz, M.Z. (2012). Clinico-histopathological studies on the correlation between some parasitic infestation on liver and ovarian efficiency in small ruminants. J. Reprod. and Infertility. 3(3): 67-76.

Gordon, H. and Sweets Jr, H.H. (1936). A simple method for the silver impregnation of reticulum. The American Journal of Pathology. 12(4): 545-552.

Ibrahim, N. (2017). Fascioliasis: Systematic review. Advances in Biological Research. 11(5): 278-285.

Labruna, M.B., Costa, F.B., Port-Carvalho, M., Oliveira, A.S., Souza, S.L.P. and Castro, M.B. (2018). Lethal fascioliasis in capybaras (Hydrochoerus hydrochaeris) in Brazil. The Journal of Parasitology. 104(2): 173-176.

Lee, U.E. and Friedman, S.L. (2011). Mechanisms of hepatic fibrogenesis. Best Practice and Research Clinical Gastroenterology. 25(2): 195-206. 
Liu, C., Tao, Q., Sun, M., Wu, J. Z., Yang, W., Jian, P. et al. (2010). Kupffer cells are associated with apoptosis, inflammation and fibrotic effects in hepatic fibrosis in rats. Laboratory Investigation. 90(12): 1805-1816.

Mehal, W.Z., Azzaroli, F. and Crispe, I.N. (2001). Immunology of the healthy liver: Old questions and new insights. Gastroenterology. 120(1): 250-260.

Mehmood, K., Zhang, H., Sabir, A.J., Abbas, R.Z., ljaz, M., Durrani, A.Z., et al. (2017). A review on epidemiology, global prevalence and economical losses of fasciolosis in ruminants. Microbial Pathogenesis. 109: 253-262.

Mendes, E.A., Vasconcelos, A.C. and dos Santos Lima, W. (2012). HISTOPATOLOGIA DA INFECÇÃO POR Fasciola hepatica EM Meriones unguiculatus. Revista de Patologia Tropical/Journal of Tropical Pathology. 41(1). https:// doi.org/10.5216/rpt.v41i1.17747.

Mendes, R.E., Zafra, R., Pérez-Écija, R.A., Buffoni, L., MartínezMoreno, Á., Tendler, M. and Pérez, J. (2010). Evaluation of local immune response to Fasciola hepatica experimental infection in the liver and hepatic lymph nodes of goats immunized with Sm14 vaccine antigen. Memorias Do Instituto Oswaldo Cruz. 105(5): 698-705.

Molina, E.C. and Skerratt, L.F. (2005). Cellular and humoral responses in liver of cattle and buffaloes infected with a single dose of Fasciola gigantica. Veterinary Parasitology. 131(1-2): 157-163.

Moreau, E., Hervé, S., Yu, Z.W. and Alain, C. (2002). Modulation of sheep lymphocyte responses by Fasciola hepatica excretory-secretory products. Veterinary Parasitology. 108(3): 207-215.
Najib, M.A., Izani, N.J.N., Amilah, W.A.W.W.N., Faez, A.M. and Shafizol, Z. (2020). A scoping review of the prevalence of fascioliasis in Malaysia and risk factors for infection. The Malaysian Journal of Medical Sciences. 27(1): 22-36.

Okoye, I.C., Egbu, F.M.I., Ubachukwu, P.O. and Obiezue, N.R. (2015). Liver histopathology in bovine fascioliasis. African Journal of Biotechnology. 14(33): 2576-2582.

Perez, J., de las Mulas, J.M., De Lara, F.C.M., Gutierrez-Palomino, P.N., Becerra-Martel, C. and Martìnez-Moreno, A. (1998). Immunohistochemical study of the local immune response to Fasciola hepatica in primarily and secondarily infected goats. Veterinary Immunology and Immunopathology. 64(4): 337-348.

Pérez, J., Ortega, J., Moreno, T., Morrondo, P., López-Sández, C. and Martinez-Moreno, A. (2002). Pathological and immunohistochemical study of the liver and hepatic lymph nodes of sheep chronically reinfected with Fasciola hepatica, with or without triclabendazole treatment. Journal of Comparative Pathology. 127(1): 30-36.

Salmo, N.A.M. (2014). Histopathological study of chronic livers Fascioliasis of cattle in Sulaimani abattoir. AL-Qadisiyah Journal of Veterinary Medicine Sciences. 13(2): 71-80.

Zafra, R., Pérez-Écija, R. A., Buffoni, L., Mendes, R.E., MartínezMoreno, A., Martínez-Moreno, F.J., et al. (2010). Evaluation of hepatic damage and local immune response in goats immunized with native glutathione S-transferase of Fasciola hepatica. Journal of Comparative Pathology. 143(2-3): 110-119. 